\title{
The importance of aminoguanidine and methylprednisolone administration in lung contusion after chest trauma
}

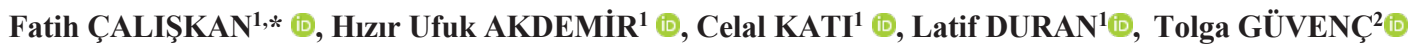 \\ ${ }^{1}$ Department of Emergency Medicine, Faculty of Medicine, Ondokuz Mayis University, Samsun, Turkey \\ ${ }^{2}$ Department of Pathology, Faculty of Veterinary Medicine, Ondokuz Mayis University, Samsun, Turkey
}

\begin{abstract}
Received: $16.03 .2021 \quad \bullet \quad$ Accepted/Published Online: 26.03.2021 • Final Version: 30.08 .2021
Abstract

This study aims to evaluate the effect of the antioxidant and anti-inflammatory properties of aminoguanidine and metylprednisolone (MP) on lung tissue in a pulmonary contusion model of rats and evaluate whether their combined use improves treatment efficacy. This study included 35 female Sprague Dawley rats weighing 250-300 grams. The rats were divided into five groups as following: Sham; Pulmonary Contusion (PC); PC+MP, PC group treated with i.p methylprednisolone; $\mathrm{PC}+\mathrm{AG}, \mathrm{PC}$ group treated with i.p Aminoguanidine; and $\mathrm{PC}+\mathrm{AG}+\mathrm{MP}, \mathrm{PC}$ group treated with Aminoguanidine and methylprednisolone. Each group had seven animals. Blood and lung tissues were studied biochemically and histopathologically. When compared groups according to serum levels of biomarkers, serum YKL-40, nitrate-nitrite, catalase, and TBARS levels were significant different. Serum YKL-40 levels were decreased after treatments in three groups. The serum YKL-40 levels in PC+AG group were lower than the other treatment groups, especially compared to $\mathrm{PC}+\mathrm{MP}(\mathrm{p}=0.028)$. Serum nitrate-nitrite levels were decreased in all treatment groups $(\mathrm{PC}+\mathrm{MP}, \mathrm{PC}+\mathrm{AG}$ and $\mathrm{PC}+\mathrm{MP}+\mathrm{AG})$. The lowest levels were measured in $\mathrm{PC}+\mathrm{MP}+\mathrm{AG}$; but there was no statistically significant difference compared to $\mathrm{PC}$ group ( $>0.05)$. Serum catalase levels were increased in all treatment groups. The higher levels were measured in $\mathrm{PC}+\mathrm{MP}+\mathrm{AG}$ than the other single treatment groups; however, $\mathrm{PC}+\mathrm{MP}+\mathrm{AG}$ and $\mathrm{PC}+\mathrm{MP}$ were statistically significant different compared to $\mathrm{PC}$ group ( $\mathrm{p}=0.001$ and $\mathrm{p}=0.002$ respectively). Serum TBARS levels were decreased in all treatment groups compared to Sham group $(\mathrm{p}<0.001)$ and $\mathrm{PC}$ group $(\mathrm{p}<0.001)$. The lowest levels were measured in $\mathrm{PC}+\mathrm{MP}+\mathrm{AG}$ compared to $\mathrm{PC}$ group $(\mathrm{p}<0.001)$. Histopathologic and immunohistochemical staining scores were decreased at all the treatment groups, especially $\mathrm{PC}+\mathrm{MP}+\mathrm{AG}$. We suggest the use of combined treatment of methylprednisolone and aminoguanidine for the treatment of pulmonary contusion.
\end{abstract}

Keywords: aminoguanidine, lung contusion, methylprednisolone, oxidative stress

\section{Introduction}

Trauma is one of the most common cause of mortality, morbidity, and hospitalization in the world. According to the Centers for Disease Control and Prevention in United States of America, 169.936 deaths occurred from unintentional injury in 2017 (1). Blunt chest injury can affect any part of thorax. Lung contusions are the most common injury occurred after blunt chest trauma in all aged trauma-patients. Patients' clinical status with lung contusions may vary from asymptomatic to severe acute lung injury (ALI) and acute respiratory distress syndrome (ARDS) that requires intensive care and results in a high mortality rate.

At the molecular level, data obtained from animal experiments supports a mediator-driven inflammatory process that further leads to respiratory compromise after chest trauma. Endothelial cell activation occurs, and it may result in mediator generation. Similarly, pro-inflammatory signaling molecules (tumor necrosis factor (TNF), IL-1 $\beta$, angiopoietin 2, vascular endothelial growth factor, platelet-activating factor and others) are released after blunt chest trauma (2). When these substances are released, systemic vascular permeability frequently increases, and it often contributes to hypovolemia and causes multiple organ failure (3).

To understand the pathophysiology at the molecular level may provoke to develop the new methods of treatment and improve the prognosis of trauma patients. Many studies have been demonstrated to clarify the pathological - physiological pathways, intra - extracellular changes, and inflammation in lung tissue $(2,4,5)$. The objective of the present study was to determine the effect of aminoguanidine and metylprednisolone (MP) on lung tissue of rats and evaluate whether their combined use improves treatment efficacy in an animal model of pulmonary contusion.

\section{Materials and methods}

\subsection{Ethical statement}

This study was approved by The Ethics Committee of Ondokuz Mayıs University for Experimental Animal Studies. Efforts were made to minimize animal suffering and reduce the number of animals used in experimental groups. All animals were treated in accordance with The World Health Organization Ethical Code for Animal Experimentation. 


\subsection{Experimental animals and procedures}

A total of 35 healthy female Sprague Dawley rats with weights of 250-300 g were used as experimental animals. Feeding and tap water were provided ad libitum. All rats were kept in windowless animal quarters with temperature automatically maintained at $24^{\circ} \mathrm{C}$ and controlled lighting (12hour light/ 12-hour dark cycle) and humidity (55-60\%).

The rats were divided into five groups as following: Sham (control); PC; PC+MP, PC group treated with i.p MP (20 mg Prednol-L; Mustafa Nevzat, Turkey); PC+AG, PC group treated with i.p AG (Aminoguanidine hemi sulfate salt; Sigma-Aldrich, St. Louis, MO, USA); and PC+AG+MP, PC group treated with $\mathrm{AG}+\mathrm{MP}$. Each group had seven animals.

The rats in the PC groups were anesthetized with ketamine hydrochloride (100 mg/kg, i.p.) and xylazine (10 mg/kg, i.p.) and subjected to chest trauma with $1.96 \mathrm{~J}$ of impact energy as described by Raghavendran K. et al. (2). The impact energy (E) of the falling weight was calculated from the following equation: $E=m(0.4 \mathrm{~kg}) \times g\left(9.8 \mathrm{~m} / \mathrm{s}^{2}\right) \times \mathrm{h}(50 \mathrm{~cm})(6)$. The rats in the PC + MP group were injected with MP i.p. once a day $(30 \mathrm{mg} / \mathrm{kg}$ injected $5 \mathrm{~min}$ after the trauma on day 1 and 5 $\mathrm{mg} / \mathrm{kg}$ from days 2 to 7) (7). The rats in the PC + AG group were administered AG i.p (150 mg/kg administered daily during one week after the trauma). The rats in the PC + MP + AG group were administered i.p. the $5 \mathrm{mg} / \mathrm{kg} /$ day doses of MP and the $150 \mathrm{mg} / \mathrm{kg} /$ day doses of AG for seven days. All rats were kept under observation until they recovered from the experimental procedure. After seven days of treatment, all rats were sacrificed with i.p. ketamine hydrochloride and xylazine injections. The lungs were removed from the thorax for histopathological and immunohistochemical analyses.

\subsection{Histopathological studies}

Lung tissue samples obtained from midsagittal slices of the lungs were fixed in 10\% formalin and embedded in paraffin. The samples were stained with hematoxylin and eosin (H\&E) for microscopic examination. A histopathological evaluation was performed in at least 8 randomly selected microscopic high-power fields from each tissue samples. Subsequently, all slides were examined by a pathologist blinded to the study groups, and they scored all microscopic slides according to degree of peribronchial inflammatory cell infiltration (PICI), alveolar septal infiltration (ASI), alveolar edema (AED), alveolar exudate (AEX), alveolar histiocytes (AHI), interstitial fibrosis (IF), granuloma (GRA), and necrosis (NEC) formation using the 4-point scale developed by Takil et al. (8) Table 1.

\subsection{Immunohistochemistry procedure}

Lung tissue samples were fixed in $10 \%$ neutral- buffered formalin and embedded in paraffin. All samples were sectioned at a thickness of $5 \mu \mathrm{m}$. Additional sections, placed on 3-aminopropyl triethoxysilane (Sigma, St. Louis, MO, USA) coated slides, were stained by the streptavidin-biotinperoxidase complex (SBPC) technique (Histostain Plus Kit;
Zymed, cat no: 85-8943, California, USA). Rabbit polyclonal anti inducible nitric oxide synthase (iNOS) antibody (1/250; Abcam, cat no: ab3523, UK) was used as primary antibody. Aminoethyl carbazole was used as the chromogen in $\mathrm{H}_{2} \mathrm{O}_{2}$ for 10 minutes, which was controlled by visual observation with a microscope. The sections were counterstained with Mayer's hematoxylin for 1 minute and rinsed with tap water. Subsequently, the sections were mounted with an aqueous mounting medium. Immunohistochemical iNOS staining of the lung tissue slides was evaluated semi quantitatively according to intensity for the differences between each experimental group (Fig. 1). Staining intensity of iNOS were recorded as faint $(-/+)$, mild $(+)$, moderate $(++)$, and strong $(+++)$. The evaluation of immunostaining was performed in at least 8 randomly selected areas per lung section, using 2 sections from each animal at $400 \times$ magnification. The final score calculated in each category for each individual rat was the mean of the scores from the sections of the lungs examined.

Table 1. Parameters for histopathologic evaluation (4-point scale)

\begin{tabular}{|c|c|c|c|c|}
\hline & $\mathbf{0}$ & $\mathbf{1}$ & $\mathbf{2}$ & $\mathbf{3}$ \\
\hline PICI & No & $\begin{array}{c}\text { No Prominent } \\
\text { germinal } \\
\text { centers of } \\
\text { lymphoid } \\
\text { follicles }\end{array}$ & $\begin{array}{c}\text { Infiltration } \\
\text { between } \\
\text { lymphoid } \\
\text { follicles }\end{array}$ & $\begin{array}{c}\text { Confluent } \\
\text { bandlike } \\
\text { form }\end{array}$ \\
\hline ASI & No & Minimal & Moderate & $\begin{array}{c}\text { Severe, } \\
\text { impending } \\
\text { of lumen }\end{array}$ \\
\hline AED & No & Focal & $\begin{array}{c}\text { In multiple } \\
\text { alveoli }\end{array}$ & $\begin{array}{c}\text { Widespread, } \\
\text { involving } \\
\text { lobules }\end{array}$ \\
\hline AEX & No & Focal & $\begin{array}{c}\text { In multiple } \\
\text { alveoli }\end{array}$ & $\begin{array}{c}\text { Prominent, } \\
\text { widespread }\end{array}$ \\
\hline AHI & No & Scattered in a & $\begin{array}{c}\text { Forming } \\
\text { flusters in } \\
\text { few alveoli } \\
\text { spaces }\end{array}$ & $\begin{array}{c}\text { Filling the } \\
\text { alveolar } \\
\text { spaces }\end{array}$ \\
\hline IF & No & Focal, & $\begin{array}{c}\text { No Focal, } \\
\text { prominent } \\
\text { fibrous } \\
\text { thickening }\end{array}$ & $\begin{array}{c}\text { Widespread, } \\
\text { prominent } \\
\text { fibrous } \\
\text { thickening }\end{array}$ \\
\hline
\end{tabular}

\subsection{Biochemical analysis \\ Sample preparation}

After the rats were sacrificed, blood samples were collected in sterile test tubes without anticoagulants. Whole blood was allowed to clot at room temperature for 30 minutes. Then, the samples were centrifuged at $3000 \mathrm{xg}$ for ten minutes at $4{ }^{\circ} \mathrm{C}$. Following centrifugation, the serum was removed and transferred into a clean tube. All samples were stored at $80^{\circ} \mathrm{C}$ 'de until analysis. A day before measuring, all samples were unfrozen at $2-80^{\circ} \mathrm{C}$.

\section{Measurement of serum TBARS levels}

TBARS were measured using the TBARS assay kit (Catalog No. 10009055, Cayman Chemical Company, Ann Arbor, MI, USA). The principle of the test is the formation of the Malondialdehyde-Thiobarbituric acid (MDA-TBA) adduct by the reaction of MDA and TBA under high temperature (90- 
$100{ }^{\circ} \mathrm{C}$ ) and acidic conditions. The concentration of the MDATBA adduct was measured colorimetrically at 530 and $540 \mathrm{~nm}$. The results have been presented in micromoles per liter.

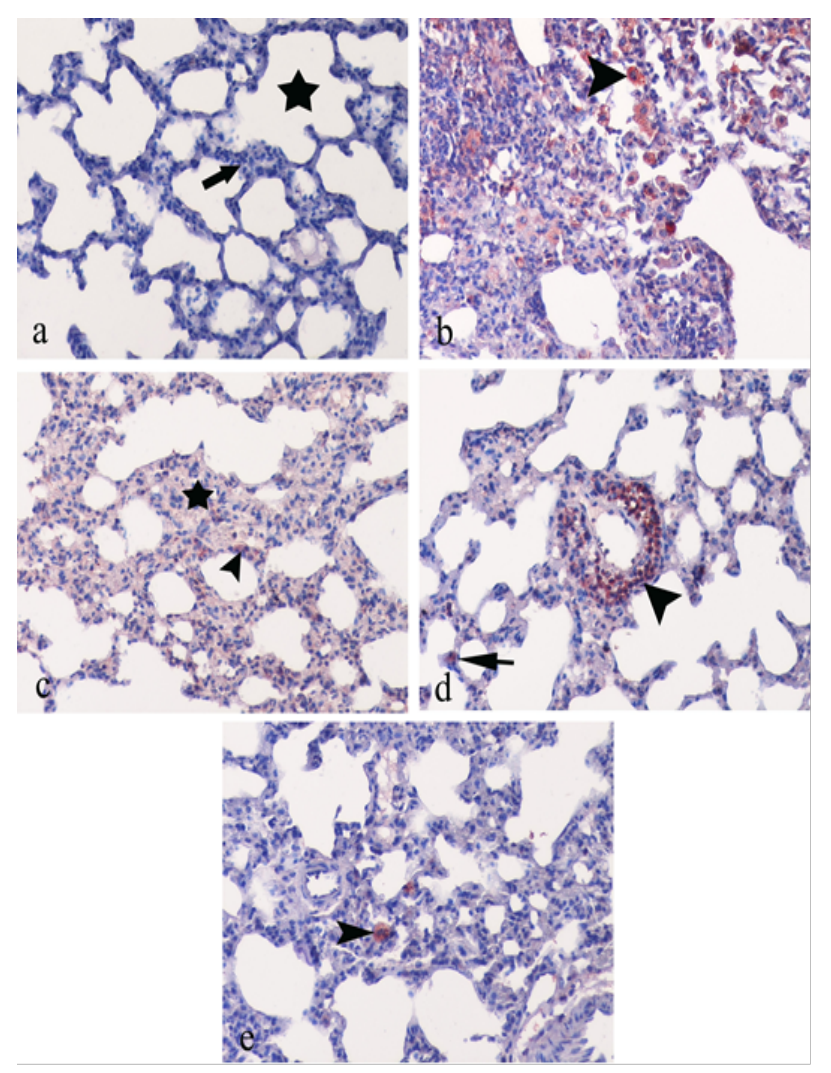

Fig. 1. Immunohistochemical evaluation of lung tissues. a) Sham group, normal alveolar structure (star) and there is no immunopositive cells in the alveolar septal tissue (arrow); b) PC group, severe immune-positive staining of alveolar macrophages (arrowhead) and interstitial tissue; c) $\mathrm{PC}+\mathrm{AG}$ group, moderate alveolar septal infiltration (star) and minimal immunopositive reaction of interstitial cells (arrow head); d) $\mathrm{PC}+\mathrm{MP}$ group, severe immunopositive reaction of the inflammatory cells in the perivascular area (arrow head) but minimal positive reaction of interstitial cells (arrow). e) $\mathrm{PC}+\mathrm{AG}+\mathrm{MP}$ group, there is minimal immunopositive reaction of interstitial cells (arrowhead). IHC staining, counter stain with Lille Mayer Alum Hematoxylin x 20. Sham, control; PC, pulmonary contusion; PC + MP, PC group treated with methylprednisolone; $\mathrm{PC}+\mathrm{AG}, \mathrm{PC}$ group treated with aminoguanidine; $\mathrm{PC}+\mathrm{MP}+\mathrm{AG}, \mathrm{PC}$ group treated with $\mathrm{MP}$ and $\mathrm{AG}$

\section{Measurement of serum Cartilage Glycoprotein 39 levels}

Serum Cartilage Glycoprotein 39 (YKL-40) levels were measured using the YKL-40 ELISA kit (CK-E90203, Hangzhou Eastbiopharm Co. Ltd., Hangzhou, China) according to manufacturer's procedures. The results of test have been presented as $\mathrm{ng} / \mathrm{mL}$ using a double antibody sandwich ELISA method.

\section{Measurement of serum Nitrate/Nitrite levels}

Serum Nitrate/Nitrite levels were measured in accordance with the procedures specified by the manufacturer using the Nitrate/Nitrite Colorimetric Assay kit (780001, Cayman Chemical Company, MI, U.S.A.). In this two-step colorimetric test, nitrate was first converted to nitrite, then nitrite to azo compound. The absorbance of this azo compound was measured photometrically at $540 \mathrm{~nm}$. Total Nitrate / Nitrite concentration was given as $\mu \mathrm{mol} / \mathrm{L}$.

\section{Measurement of serum Catalase levels}

Serum catalase levels were measured in accordance with the procedures specified by the manufacturer using Catalase Assay kit (707002, Cayman Chemical Company, MI, U.S.A.), a colorimetric test based on formaldehyde formation. Test results were given in $\mathrm{nmol} / \mathrm{min} / \mathrm{ml}$.

\subsection{Statistical analysis}

Biochemical results and histopathological scores were analyzed using IBM SPSS 21.0 for Windows. The results were presented as median (minimum/maximum) or mean \pm standard deviation. Statistical differences between different groups were analyzed with one-way ANOVA and Tukey's and Tamhane tests were used for post hoc in parametric data. Kruskal Wallis were used for group analysis as a nonparametric test. Homogeneity of variance were made to all groups. Differences were considered significant at $\mathrm{p}<0.05$.

\section{Results}

\subsection{Biochemical examination}

When compared groups according to serum levels of biomarkers, serum YKL-40, nitrate-nitrite, catalase, and TBARS levels were significant different $(\mathrm{p}=0.002, \mathrm{p}=0.006$, $\mathrm{p}<0.001$ and $\mathrm{p}<0.001$ respectively), (Table 2 ).

Table 2. The comparison of serum YKL-40, Nitrate-Nitrite, Catalase and TBARS levels in all experimental groups

\begin{tabular}{|c|c|c|c|c|}
\hline & YKL-40 $(\mathbf{n g} / \mathbf{m l})$ & Nitrate-Nitrite $(\boldsymbol{\mu M} / \mathbf{l})$ & Catalase $(\mathbf{n m o l} / \mathbf{m i n} / \mathbf{m L})$ & TBARS $(\boldsymbol{\mu m o l} / \mathbf{l})$ \\
\hline Sham & $0.62 \pm 0.09$ & $6.86 \pm 1.37$ & $120.85 \pm 34.40$ & $7.14 \pm 1.01$ \\
\hline PC & $0.77 \pm 0.04^{\mathrm{a}}$ & $21.14 \pm 7.37^{\mathrm{a}}$ & $32.60 \pm 20.23^{\mathrm{a}}$ & $17.50 \pm 2.12^{\mathrm{a}}$ \\
\hline PC + MP & $0.75 \pm 0.03$ & $18.66 \pm 8.03$ & $98.14 \pm 32.30^{\mathrm{b}}$ & $12.42 \pm 1.40^{\mathrm{b}}$ \\
\hline PC + AG & $0.63 \pm 0.11^{\mathrm{b}}$ & $18.27 \pm 8.66$ & $75.04 \pm 31.27$ & $10.84 \pm 1.91^{\mathrm{b}}$ \\
\hline PC + MP + AG & $0.68 \pm 0.05$ & $15.13 \pm 6.59$ & $101.75 \pm 27.29^{\mathrm{b}}$ & $10.25 \pm 0.92^{\mathrm{b}}$ \\
\hline
\end{tabular}

The values were given as mean \pm standard deviation. Sham, control; PC, pulmonary contusion; PC + MP, PC group treated with methylprednisolone; PC + AG, PC group treated with aminoguanidine; PC + MP + AG, PC group treated with MP and AG; YKL-40, human cartilage glycoprotein 39 (chitinase-3-like protein-1); TBARS, thiobarbituric acid reactive substances. The comparisons of groups were abbreviated as "a" and "b". "a" means significantly different $($ at $p<0.05)$ from sham group. "b" means significantly different (at $p<0.05)$ from PC group 
According to serum YKL-40 levels, PC group was statistically significant different compared to Sham group $(p=0.011)$. Serum YKL-40 levels were decreased after treatments in three groups. The serum YKL-40 levels in $\mathrm{PC}+\mathrm{AG}$ group were lower than the other treatment groups, especially compared to $\mathrm{PC}+\mathrm{MP}(\mathrm{p}=0.028)$. There was a statistically significant difference only in $\mathrm{PC}+\mathrm{AG}$ group compared to PC group ( $\mathrm{p}=0.013)$. However, $\mathrm{PC}+\mathrm{MP}$ group was significantly statistical different compared to Sham group $(\mathrm{p}=0.024)($ Table 2$)$.

According to serum nitrate-nitrite levels, PC group was significant different compared to Sham group $(p=0.019)$. Serum nitrate-nitrite levels were decreased in all treatment groups $(\mathrm{PC}+\mathrm{MP}, \mathrm{PC}+\mathrm{AG}$ and $\mathrm{PC}+\mathrm{MP}+\mathrm{AG})$. The lowest levels were measured in $\mathrm{PC}+\mathrm{MP}+\mathrm{AG}$; but there was no statistically significant difference compared to $\mathrm{PC}$ group ( $>0.05)$, (Table 2). When $\mathrm{PC}+\mathrm{MP}+\mathrm{AG}$ compared to $\mathrm{PC}+\mathrm{AG}$ and $\mathrm{PC}+\mathrm{MP}$, there was no statistically significant difference $(\mathrm{p}>0.05)$.

According to serum catalase levels, PC group with the highest levels was significant different compared to Sham group $(p<0.001)$. Serum catalase levels were increased in all treatment groups. The higher levels were measured in $\mathrm{PC}+\mathrm{MP}+\mathrm{AG}$ than the other single treatment groups; however, $\mathrm{PC}+\mathrm{MP}+\mathrm{AG}$ and $\mathrm{PC}+\mathrm{MP}$ were statistically significant different compared to $\mathrm{PC}$ group $(\mathrm{p}=0.001$ and $\mathrm{p}=0.002$ respectively). When $\mathrm{PC}+\mathrm{MP}+\mathrm{AG}$ compared to $\mathrm{PC}+\mathrm{MP}$, there was no statistically significant difference $(p>0.05)$, (Table 2$)$.

According to serum TBARS levels, PC group was significant different compared to Sham group $(p<0.001)$. Serum TBARS levels were decreased in all treatment groups compared to Sham group $(p<0.001)$ and PC group $(p<0.001)$. The lowest levels were measured in $\mathrm{PC}+\mathrm{MP}+\mathrm{AG}$ compared to $\mathrm{PC}$ group $(\mathrm{p}<0.001)$, (Table 2$)$. When compared to $\mathrm{PC}+\mathrm{MP}, \mathrm{PC}+\mathrm{MP}+\mathrm{AG}$ was statistically significant different $(\mathrm{p}=0.036)$; but there was no significant difference compared to $\mathrm{PC}+\mathrm{AG}(\mathrm{p}>0.05)$, (Table 2$)$.

\subsection{Histopathological and immunohistochemical findings} Images of histopathological sections belonged to all study groups are shown in Fig 2. All groups compared to PC and sham according to histopathologic scores including PICI, ASI, AED, AEX and AHI. Scores of histopathological and immunohistochemical staining belonged to all study groups are shown in Table 3. There were statistically significant differences in the distribution of PICI, ASI, AED, AEX and AHI without IF across groups $(\mathrm{p}<0.001, \mathrm{p}<0.001, \mathrm{p}<0.001$, $\mathrm{p}<0.001$, and $\mathrm{p}<0.001)$; IF scores were similar in all groups (measured IF score: 0$),(\mathrm{p}>0.05)$.

After the histopathological evaluations of groups, there was a significant statistical difference between Sham and PC group $(p<0.001)$. Median of PICI scores in three treatment groups was 1. $\mathrm{PC}+\mathrm{MP}$ group was significant different compared to Sham group according to PICI $(\mathrm{p}=0.043)$. There was no significant difference in $\mathrm{PC}+\mathrm{AG}$ compared to $\mathrm{PC}$ according to PICI scores $(p=0.077)$. $P C+M P+A G$ was statistically significant different to compared to $\mathrm{PC}$ group according to PICI scores $(\mathrm{p}=0.008)$. In order to ASI scores, PC group was significant different compared to Sham $(p<0.001)$. Although median of all treatment group in ASI scores were lower than PC group, there was no statistically significant difference compared to $\mathrm{PC}(\mathrm{p}>0.05)$. But $\mathrm{PC}+\mathrm{AG}$ was statistically significant different than Sham according to ASI scores $(p=0.006)$. According to AED scores, PC was statistically significant different compared to Sham $(\mathrm{p}<0.001) . \quad \mathrm{PC}+\mathrm{MP}+\mathrm{AG}$ had the lowest median according AED scores compared the other treatment groups. But there was statistically significant difference in $\mathrm{PC}+\mathrm{MP}+\mathrm{AG}$ compared to PC group ( $p=0.022$ ). According to AEX scores, there was a statistically significant difference between Sham and $\mathrm{PC}$ groups $(\mathrm{p}=0.001)$.

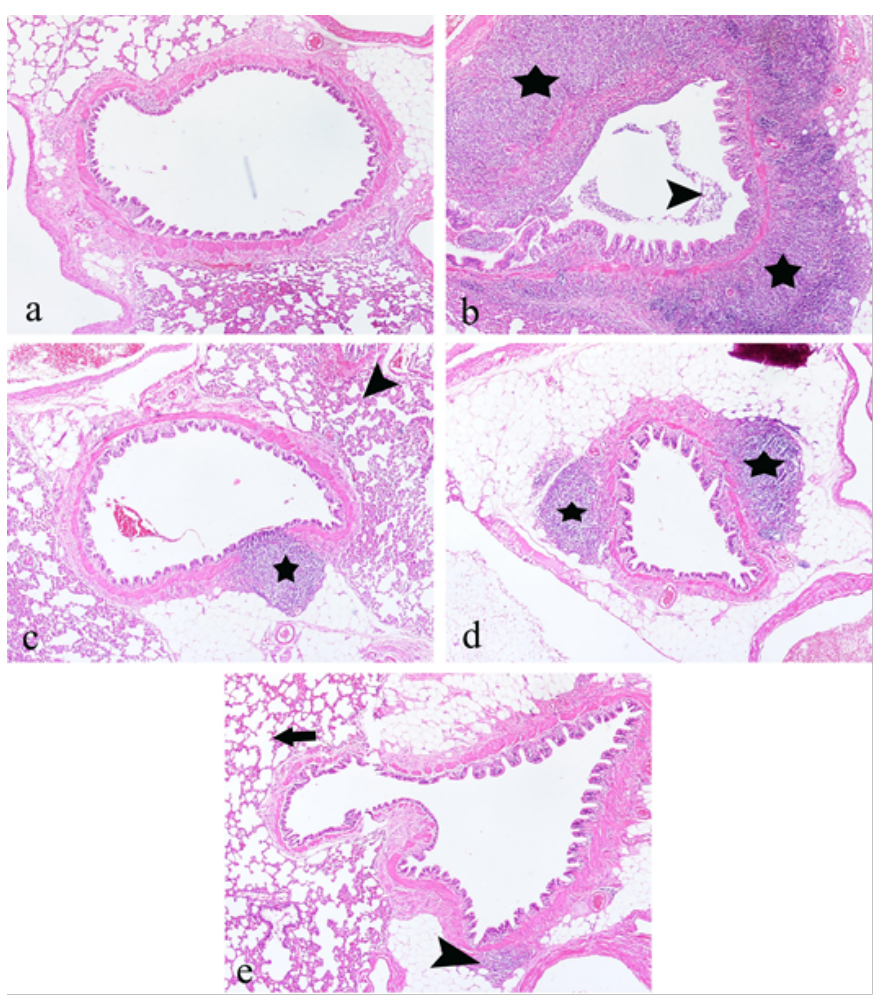

Fig. 2. Histopathological evaluation of lung tissues. a) Sham group, normal histopathologic appearance of lung tissues, there is no peribronchial infiltration and alveolar septal infiltration, HE $\mathrm{x} 4$; b) PC group, there is severe infiltration with lymphoid follicles in the bronchial wall (stars) and necrotic cells in the bronchial lumen (arrow heads) HE x 4; c) PC + AG group, there is only one lymphoid follicle with prominent germinal center in the bronchial wall (star) and minimal alveolar septal infiltration (arrow head) HE x 4; d) PC + MP group, there are two lymphoid follicles with prominent germinal center in the bronchial wall (stars) $\mathrm{HE} \mathrm{x} \mathrm{4;} \mathrm{e)} \mathrm{PC}+\mathrm{AG}+$ MP group, minimal mononuclear cell infiltration in the peribronchial area (arrowhead) and normal alveolar tissue (arrow) HE x4. Sham, control; PC, pulmonary contusion; PC + MP, PC group treated with methylprednisolone; $\mathrm{PC}+\mathrm{AG}, \quad \mathrm{PC}$ group treated with aminoguanidine; $\mathrm{PC}+\mathrm{MP}+\mathrm{AG}, \mathrm{PC}$ group treated with $\mathrm{MP}$ and $\mathrm{AG}$ 
Table 3. The comparison of histopathologic and immunohistochemical scores between all groups

\begin{tabular}{|c|c|c|c|c|c|}
\hline & Sham & PC & PC+MP & PC+AG & $\begin{array}{c}\text { PC+MP+A } \\
\text { G }\end{array}$ \\
\hline PICI & 0 & $3(2-3)^{\mathrm{a}}$ & $1(0-2)$ & 1 & $1(0-1)^{\mathrm{b}}$ \\
\hline ASI & 0 & $2(1-2)^{\mathrm{a}}$ & $1(0-2)^{\mathrm{b}}$ & $1(1-2)$ & $1(0-1)^{\mathrm{b}}$ \\
\hline AED & 0 & $2(1-2)^{\mathrm{a}}$ & $1(0-1)$ & $1(0-1)$ & $0(0-1)^{\mathrm{b}}$ \\
\hline AEX & 0 & $2(1-2)^{\mathrm{a}}$ & $1(0-1)$ & $1(0-1)$ & $0(0-1)^{\mathrm{b}}$ \\
\hline AHI & 0 & $2(1-2)^{\mathrm{a}}$ & $1(0-1)$ & $1(0-1)$ & $0(0-1)^{\mathrm{b}}$ \\
\hline IF & 0 & 0 & 0 & 0 & 0 \\
\hline IHC & 0 & $2(1-3)^{\mathrm{a}}$ & $2(0-2)$ & $1(0-2)$ & $0(0-1)^{\mathrm{b}}$ \\
\hline
\end{tabular}

The values were given as median (min-max). PICI, peribronchial inflammatory cell infiltration; ASI, alveolar septal infiltration; AED, alveolar edema; AEX, alveolar exudate; AHI, alveolar histiocytes; IF, interstitial fibrosis; IHC, immunohistochemical; Sham, control; PC, pulmonary contusion; PC + MP, PC group treated with methylprednisolone; $\mathrm{PC}+\mathrm{AG}, \mathrm{PC}$ group treated with aminoguanidine; $\mathrm{PC}+\mathrm{MP}+\mathrm{AG}, \mathrm{PC}$ group treated with $\mathrm{MP}$ and AG. The comparisons of groups were abbreviated as "a" and "b". "a" means significantly different $($ at $p<0.05)$ from sham group. "b" means significantly different (at $\mathrm{p}<0.05$ ) from $\mathrm{PC}$ group

$\mathrm{PC}+\mathrm{MP}+\mathrm{AG}$ group has the lowest median according to AEX scores compared to the other treatment groups. $\mathrm{PC}+\mathrm{MP}+\mathrm{AG}$ was a statistically significant different compared to $\mathrm{PC}$ group ( $\mathrm{p}=0.004$ ). According to AHI scores, there was a statistically significant difference between Sham and PC groups $(p<0.001)$. The lowest median of AHI score was in $\mathrm{PC}+\mathrm{MP}+\mathrm{AG}$ group between treatment groups. $\mathrm{PC}+\mathrm{MP}+\mathrm{AG}$ group was statistically significant different compared to $\mathrm{PC}$ according to AHI scores $(\mathrm{p}=0.006)$. IF score of all groups including Sham, PC and three treatment groups was $0 / 4$ and all groups were similar.

Images of immunohistochemical staining sections belonged to all study groups are shown in Fig. 1. According to the immunohistochemical evaluation, there was a statistically significant difference between groups $(p<0.001)$. There was no statistically significant difference between Sham and PC groups $(p=0.631)$. The lowest median of IHC score was in $\mathrm{PC}+\mathrm{MP}+\mathrm{AG}$ group and this combined treatment group, $\mathrm{PC}+\mathrm{MP}+\mathrm{AG}$ was significant different compared to $\mathrm{PC}$ group $(p=0.008)$. To IHC staining scores, $P C+M P$ was statistically significant different compared to Sham $(\mathrm{p}=0.033)$. Histopathologic and immunohistochemical staining scores of all groups were shown in Table 3.

\section{Discussion}

The presence of pulmonary contusion is an important risk factor in the progression of ALI to ARDS with increased rate of mortality (2). Therefore, the effects of antioxidant and antiinflammatory properties of aminoguanidine and methylprednisolone on damage lung tissue in a pulmonary contusion rat model were evaluated in this study.

According to results, the combined administration of aminoguanidine and methylprednisolone significantly reduced all the histopathologic scores of pulmonary contusions (PICI, AED, AEX, AHI and IHC). While the combined administration of AG and MP had lowest scores of PICI, AED, AEX, AHI and IHC; the combined treatment was not significant different compared to the single administration of AG and the single use of MP separately. At the same time, both single therapy of $\mathrm{AG}$ and $\mathrm{MP}$ reduced the histopathologic scores even though not as the combined administration of AG and MP. This suggests the availability of aminoguanidine as an alternative to methylprednisolone to avoid its side effects of steroidal drugs.

YKL-40 (chitinase-3-like protein-1 (Chi3-11), breast regression protein 39 (BRP-39) and chondrex) is a proinflammatory glycopeptide that belongs to the family of chitinase like proteins. It is expressed in many cell types including ductal and airway epithelial cells (9) and YKL-40 increases in presence of inflammation, tissue remodeling and cancer. YKL-40 levels are a predictor of all-cause mortality in the elderly (10) and have a significant association with rates of overall and cardiovascular mortality (11). The exact biological activities are yet to be identified (9). In this study, the lowest level of YKL-40 was found in the group treated aminoguanidine which is significantly different compared to $\mathrm{PC}$ group. Interestingly, there was no significant difference between $\mathrm{PC}$ and combined administration of $\mathrm{AG}$ and MP which also reduced the YKL-40 levels compared to PC.

Nitric oxide (NO) plays many physiological and pathophysiological roles in widespread fields. NO, synthesized in various tissues and cells, is vasodilator substance, neurotransmitter, and a killer molecule in the immune system (12). The production of NO, synthesized by NO synthase (NOS) catalytic action. It is usually evaluated by measuring nitrates and nitrites as the final stable oxidized products of its metabolism.

The sum of nitrites and nitrates (named NOx) is a good indicator of NO formation, and it shows NOS activities in many pathophysiological conditions (13). However, it is difficult to measure NO directly because NO is quite short lived. Alternatively, NOx (nitrite and nitrate) is measured as an indirect marker of NO formation. However, serum or plasma NOx concentrations are influenced by diseases such as heart failure, sepsis, and liver cirrhosis (12). In this study, the PC group that had the highest level of serum nitrate-nitrite levels was significantly different compared to Sham group. However, the combined treatment group $(\mathrm{PC}+\mathrm{MP}+\mathrm{AG})$ had lower levels compared to $\mathrm{PC}, \mathrm{PC}+\mathrm{AG}$ and $\mathrm{PC}+\mathrm{MP}$, but there was no statistically difference between groups.

The term "oxidative stress" indicates that the antioxidants status of cells and tissues is altered exposure to oxidants that 
cause the diseases. The reducing environment is related to the interaction of oxidative metabolism and antioxidant substances and enzymes which serve to remove reactive oxygen species such as thioredoxin, vitamin $\mathrm{E}$ and $\mathrm{C}$, glutathione, superoxide dismutase (SOD), catalase, the selenium dependent glutathione and thioredoxin hydroperoxides (14). This situation plays an important role in lung damage.

Catalase, present in peroxisomes, catalyzes the decomposition of hydrogen peroxide $(15,16)$. In this study, PC group was significant different compared to Sham group. The combined treatment significantly increased the catalase levels as similar as in the group treated with MP.

To evaluate free radical generation and peroxidative damage in the airways, the measurement of hydrogen peroxide ( $\mathrm{H} 2 \mathrm{O} 2)$ and thiobarbituric acid reactive substances (TBARS) is suggested. Hydrogen peroxide and/or TBARS increase in many inflammatory lung injuries. TBARS are occurred after polyunsaturated fatty acid peroxidation; however, they are also formed during oxidative injury of DNA, proteins, or carbohydrates. Therefore, TBARS is commonly used marker of oxidative stress (17). In this study, the increased levels of TBARS were found in PC group; controversially all the treatment groups had lower TBARS levels. The combined group was significantly different compared to $\mathrm{PC}$ as similar as the other treatment groups $\mathrm{PC}+\mathrm{AG}$ and $\mathrm{PC}+\mathrm{MP}$.

Steroids become prominent with their strong antiinflammatory functions. Although the administration of high doses of steroids are used in the practice, the use of steroids for the treatment of pulmonary contusion has rarely addressed in the literature and this does not provide enough evidence. Fransz et al. (18) administered methylprednisolone 30 minutes after experimental pulmonary contusion model in dogs. The weight ratio of contused to normal lung was significantly decreased in treated animals and the volume of injury was less on postmortem. Since the animals were killed, the effect of steroids on recovery and survival could not be assessed. In a small retrospective human study, Svennevig et al. (19) concluded that the mortality in severe chest injury was reduced using steroids (20). Although there are studies suggesting that steroids may be useful in lung contusion, the presence of defects on study randomization, administration of steroid and other deficiencies in these studies are noteworthy. In this study, $\mathrm{PC}+\mathrm{MP}$ group was lower histopathologic scores compared to $\mathrm{PC}$ group; but $\mathrm{PC}+\mathrm{MP}$ group was significant different in only ASI score compared to PC. In addition, $\mathrm{PC}+\mathrm{MP}$ group was significant different according the TBARS levels compared to PC group; but there was no significant difference compared to combined therapy group (PC+AG+MP). However, in this study, single MP treatment increased the catalase levels and decreased the TBARS levels.

In a conclusion, we suggest the use of combined treatment of methylprednisolone and aminoguanidine for the treatment of pulmonary contusion. This treatment regimen seems to be more effective for treating lung injury after blunt chest trauma.

\section{Conflict of interest}

The authors declare that they have no conflict of interest.

\section{Acknowledgments}

The authors thank Naci MURAT (Ondokuz Mayıs University, Department of Statistics, Samsun, Turkey) for controlling the analysis of statistical data.

\section{References}

1. 10 Leading Causes of Death by Age Group, United Sates - 2017 . Centers For Disease Control and Prevention. [Internet]. February 7, 2019; Available from: https://www.cdc.gov/injury/wisqars/pdf/leading_causes_of_death _by_age_group_2017-508.pdf.

2. Raghavendran K, Davidson BA, Helinski JD, Marschke CJ, Manderscheid P, Woytash JA, et al. A rat model for isolated bilateral lung contusion from blunt chest trauma. Anesth Analg. 2005 Nov;101(5):1482-9. doi: 10.1213/01.ANE.0000180201.25746.1F.

3. Matthay MA, Ware LB, Zimmerman GA. The acute respiratory distress syndrome. J Clin Invest. 2012 Aug;122(8):2731-40. doi: 10.1172/JCI60331.

4. Akgül AG, Şahin D, Temel U, Eliçora A, Dillioğlugil M, Maral Kır H, et al. Effect of nitric oxide synthase inhibitors in acute lung injury due to blunt lung trauma in rats. Turk Gogus Kalp Damar Cerrahisi Derg. 2019 Jan 1;27(1):63-72. doi: 10.5606/tgkdc.dergisi.2019.15936.

5. Hoth JJ, Stitzel JD, Gayzik FS, Brownlee NA, Miller PR, Yoza $\mathrm{BK}$, et al. The pathogenesis of pulmonary contusion: an open chest model in the rat. J Trauma. 2006 Jul;61(1):32-44; discussion 44-5. doi: 10.1097/01.ta.0000224141.69216.aa.

6. Miller PR, Croce MA, Bee TK, Qaisi WG, Smith CP, Collins GL, et al. ARDS after pulmonary contusion: accurate measurement of contusion volume identifies high-risk patients. J Trauma. 2001 Aug;51(2):223-8; discussion 229-30. doi: 10.1097/00005373-200108000-00003.

7. Teng D, Pang QF, Yan WJ, Zhao Xin W, Xu CY. The harmful effect of prolonged high-dose methylprednisolone in acute lung injury. Int Immunopharmacol. 2013 Feb;15(2):223-6. doi: 10.1016/j.intimp.2012.12.004.

8. Takil A, Umuroğlu T, Göğüş YF, Eti Z, Yildizeli B, Ahiskali R. Histopathologic effects of lipid content of enteral solutions after pulmonary aspiration in rats. Nutrition. 2003 Jul-Aug;19(78):666-9. doi: 10.1016/s0899-9007(03)00057-1.

9. Lee CG, Da Silva CA, Dela Cruz CS, Ahangari F, Ma B, Kang $\mathrm{MJ}$, et al. Role of chitin and chitinase/chitinase-like proteins in inflammation, tissue remodeling, and injury. Annu Rev Physiol. 2011; 73:479-501. doi: 10.1146/annurev-physiol-012110142250 .

10. Johansen JS, Pedersen AN, Schroll M, Jørgensen T, Pedersen BK, Bruunsgaard H. High serum YKL-40 level in a cohort of octogenarians is associated with increased risk of all-cause mortality. Clin Exp Immunol. 2008 Feb;151(2):260-6. doi: 10.1111/j.1365-2249.2007.03561.

11. Rathcke CN, Raymond I, Kistorp C, Hildebrandt P, Faber J, Vestergaard H. Low grade inflammation as measured by levels of YKL-40: association with an increased overall and 


\section{Calıskan et al. / J Exp Clin Med}

cardiovascular mortality rate in an elderly population. Int $\mathrm{J}$ Cardiol. 2010 Aug 6;143(1):35-42. doi: 10.1016/j.ijcard.2009.01.043.

12. Watanabe T, Akishita M, Toba K, Kozaki K, Eto M, Sugimoto $\mathrm{N}$, et al. Influence of sex and age on serum nitrite/nitrate concentration in healthy subjects. Clin Chim Acta. 2000 Nov;301(1-2):169-79. doi: 10.1016/s0009-8981(00)00340-5.

13.Zunić G, Colić M, Vuceljić M. Nitrite to nitrate molar ratio is inversely proportional to oxidative cell damages and granulocytic apoptosis at the wound site following cutaneous injury in rats. Nitric Oxide. 2009 Jun;20(4):264-9. doi: 10.1016/j.niox.2009.02.002.

14. Cadenas E, Packer L. Handbook of antioxidants: Marcel Dekker New York; 2002.

15. Kumar V, Abbas AK, Aster JC. Robbins basic pathology e-book: Elsevier Health Sciences; 2017.

16. Davies KJ. Oxidative stress: the paradox of aerobic life. Biochem Soc Symp. 1995; 61:1-31. doi: 10.1042/bss0610001.
17. Puntel RL, Nogueira CW, Rocha JB. Krebs cycle intermediates modulate thiobarbituric acid reactive species (TBARS) production in rat brain in vitro. Neurochem Res. 2005 Feb;30(2):225-35. doi: 10.1007/s11064-004-2445-7.

18. Franz JL, Richardson JD, Grover FL, Trinkle JK. Effect of methylprednisolone sodium succinate on experimental pulmonary contusion. J Thorac Cardiovasc Surg. 1974 Nov;68(5):842-4.

19. Svennevig JL, Pillgram-Larsen J, Fjeld NB, Birkeland S, Semb G. Early use of corticosteroids in severe closed chest injuries: a 10-year experience. Injury. 1987 Sep;18(5):309-12. doi: 10.1016/0020-1383(87)90048-9.

20. Simon B, Ebert J, Bokhari F, Capella J, Emhoff T, Hayward T 3rd, et al; Eastern Association for the Surgery of Trauma. Management of pulmonary contusion and flail chest: an Eastern Association for the Surgery of Trauma practice management guideline. J Trauma Acute Care Surg. 2012 Nov;73(5 Suppl 4): S351-61. doi: 10.1097/TA.0b013e31827019fd. 